\title{
FUNÇÃO NORMATIVA DAS AGÊNCIAS REGULADORAS: UMA NOVA CATEGORIA DE DIREITO ADMINISTRATIVO?
}

Sérgio Guerra

RULEMAKING FUNCTION OF REGULATORY AGENCIES: A NEW TYPE OF ADMINISTRATIVE LAW?

\section{RESUMO}

A REALIDADE ECONÔMICA E TECNOLÓGICA NÃO PODE SER EXPLICITADA COMPLETAMENTE EM NORMAS; ELAS DEPENDEM, BASICAMENTE, DA REALIDADE SOCIAL E ECONÔMICA DO MOMENTO. DEVEM SER LEVAdAS EM CONSIDERAÇÃO TANTO AS RaZÖES PASSADAS QUANTO OS EFEITOS PROSPECTIVOS. AlÉM DESSAS CONSIDERAÇÕES, HÁ INÚMEROS TERMOS TÉCNICOS EMPREGADOS NAS NORMAS DE CUNHO ECONÔMICO, MUITOS DELES COM GRANDE INDETERMINAÇÃO, E, POR ISSO, NECESSITAM DE CERTA MARGEM DE APRECIAÇÃO DIANTE DO CASO CONCRETO. Registre-SE AINDA a NECESSIDADE DE PERIÓDICAS REFORMAS REGULATÓRIAS, NOTADAMENTE EM ATIVIDADES ECONÔMICAS QUE ABRANGEM OSCILAÇÕES DE MERCADO E MUITOS COMPONENTES TECNOLÓGICOS ESTE ARTIGO EXAMINA ESSAS QUESTÕES SOB O PONTO DE VISTA DOGMÁTICO DA COMPETÊNCIA DAS AgÊNCIAS REgULADORAS PARA A EDIÇĀO DE NORMAS QUE CONTEMPLEM NOVA FASE DO DIREITO ADMINISTRATIVO.

\section{PALAVRAS-CHAVE}

Direito público, Direito administrativo, Organização ADMINISTRATIVA BRASILEIRA, AgÊNCIAS REgULADORAS, FUNÇÕES NORMATIVAS

\begin{abstract}
THE TECHNOLOGICAL AND ECONOMIC REALITY CAN NOT BE EXPLAINED ENTIRELY IN STANDARDS; ARE BASICALLY DEPENDENT ON THE SOCIAL AND ECONOMIC REALITY OF THE MOMENT. SHOULD BE TAKEN INTO ACCOUNT BOTH THE PAST AND THE REASONS PROSPECTIVE EFFECT. BEYOND THESE CONSIDERATIONS, THERE ARE MANY TECHNICAL TERMS USED IN THE STANDARDS OF ECONOMIC NATURE, MANY WITH GREAT VAGUENESS, AND THAT, THEREFORE, REQUIRE SOME DISCRETION ON THE CASE. JOIN THE NEED FOR PERIODIC REGULATORY REFORMS, NOTABLY IN ECONOMIC ACTIVITIES WHICH INCLUDE MARKET FLUCTUATIONS AND MANY TECHNOLOGICAL COMPONENTS THIS ARTICLE EXAMINES THESE ISSUES FROM THE DOGMATIC POINT OF VIEW OF THE COMPETENCE OF REGULATORY AGENCIES TO ISSUE REGULATIONS RULES THAT ADDRESS NEW PHASE OF ADMINISTRATIVE LAW.

\section{KEYWORDS}

PUBLIC LAW, AdMINISTRATIVE LAW, BRAZILIAN ADMINISTRATIVE ORGANIZATION, REGULATORY COMMISSIONS,

RULEMAKING FUNCTION
\end{abstract}

\section{INTRODUÇÃO}

O legislador, ao atribuir ao Poder Executivo tarefas públicas, está legitimado para conferir a esse poder - e, de fato, o confere com toda normalidade - um âmbito de responsabilidade própria, sobretudo na avaliação de questões técnicas, na ponderação de interesses contraditórios e na apreciação das evoluções futuras. ${ }^{*}$ As modificações na prestação dos serviços públicos se realizam em conformidade com a 
dinâmica da competência mercadológica. O Estado, dessa forma, tem de ponderar sua capacidade de resposta com o objetivo de alcançar os fins impostos pelo interesse público. ${ }^{1}$

Assim, é plausível sustentar que a evolução das escolhas administrativas caminha para uma nova fase nos tempos atuais, que não nega a necessidade de se ampliar a atuação estatal executiva. Se, de um lado, o poder de decisão das questões de natureza política primária compete ao Poder Legislativo na edição de normas jurídicas, por outro é indisputável que a lei não consegue disciplinar o direito nos detalhes que a solução dos problemas cotidianos exige. ${ }^{2}$ Por isso, há necessidade de que o Poder Executivo tenha, em muitas situações, de atuar sem uma conduta totalmente predeterminada por uma regra legal, sempre, porém, balizado por certos limites jurídicos.

Nesse contexto, a doutrina publicista, desde remota data, trilha o caminho do poder regulamentar para a consecução de tal desiderato, fundamentando, nessa linha de pensamento, a impossibilidade da simples aplicação mecânica da lei pelo administrador público, sem qualquer inovação.

Um dos debates travados no campo doutrinário e pretoriano refere-se à função normativa exercida pelas entidades reguladoras independentes, notadamente, as Agências reguladoras de serviços públicos e atividades econômicas. Parece não haver dúvidas quanto à juridicidade de entidades reguladoras exercerem uma função normativa secundária, desde que observadas as normas hierarquicamente superiores, a exemplo de diversas outras autarquias, especiais ou não.

Compreende-se essa função normativa como não sendo primária, e sim secundária, haja vista que, entre nós, a função normativa primária é precípua do Poder Legislativo, sendo exercida de forma extravagante pelo Poder Executivo, seja por meio de medidas provisórias ou delegação legislativa ${ }^{3}$ - casos em que não se enquadra a função normativa ora em comento.

A questão, em si, é saber em qual categoria de direito administrativo essas normas regulatórias se enquadram.

Objetivamente, em nossa doutrina administrativista, tanto os que defendem a função normativa de entidades independentes do Poder Executivo Central, como, por exemplo, as agências reguladoras,${ }^{4}$ quanto os que são contrários, ${ }^{5}$ conduzem o tema para esse campo de questões.

São várias as denominações utilizadas para categorizar a função normativa do Poder Executivo. Eis algumas delas: (1) regulamento decorrente de delegação inominada; (2) regulamento autônomo; (3) deslegalização; (4) regulamento delegado ou autorizado; ${ }^{6}$ (5) capacidade normativa de conjuntura $;^{7}$ (6) remissões normativas ${ }^{8}$ e até mesmo (7) discricionariedade técnica.

Seja qual for a nomenclatura adotada, além da modalidade tradicional da regulamentação secundária, existem aquelas tipicamente regulatórias. De fato, as entidades 
reguladoras editam normas que, indiscutivelmente, afetam direitos e obrigações dos cidadãos. Exemplo dessas normas é a Resolução n. 460, de 19 de março de 2007, da Anatel, que criou o instituto da portabilidade de números de celulares. Não está expressamente em lei; contudo, foi editada e está sendo cumprida por todos. É relevante para a competição entre as operadoras e que beneficia o cidadão: o chamado "equilíbrio sistêmico".

Como se vê, é extremamente difícil submeter uma norma dessa categoria a uma ordem hierárquica definida no modelo tradicional.

Há noções próprias do direito econômico (que afetam a sociedade e, por isso, despontam o direito administrativo econômico) que o Direito não conhecia até então. "Por exemplo de actos que, para satisfazer à necessidade de maior maleabilidade da matéria económica, são, ao mesmo tempo, menos imperativos, menos estáveis e menos precisos que os actos administrativos habituais". ${ }^{9}$

Nesse contexto, destaca-se a importância de compreender a escolha regulatória como sendo uma nova categoria das escolhas administrativas. Na regulação de atividades econômicas pelo Estado, a estrutura estatal necessária para equilibrar os subsistemas regulados, ajustando as falhas do mercado, ponderando-se diversos interesses ambivalentes, não se enquadra no modelo positivista clássico e moderno, ${ }^{10}$ haja vista sua patente singularidade. ${ }^{11}$

Ademais, a regulação setorial descentralizada tem mais condições de enfrentar os desafios da "reflexividade da vida social" que consiste no fato de que as práticas sociais são constantemente examinadas e reformadas à luz de informação renovada sobre essas próprias práticas, alterando, dessa forma, seu caráter constitutivamente. ${ }^{12}$

Nesse contexto, Floriano Azevedo Marques Neto anota que a atividade regulatória é espécie do gênero atividade administrativa; contudo, trata-se de uma espécie bastante peculiar. É na moderna atividade regulatória estatal que melhor se manifesta o novo paradigma de direito administrativo, de caráter menos autoritário e mais consensual, aberto à interlocução com a sociedade e permeado pela participação do administrado. ${ }^{13}$

Ainda que se cogite a existência de diversos graus de vinculação do regulador público às regras legais, parece ser indisputável que, dada a tecnicidade encontrada em ambientes sistêmicos (aviação civil, telecomunicações, sistema financeiro, etc.), passa a ser missão do ente regulador encontrar, na autorreferência do sistema, uma solução de concordância prática entre as normas legais, em tese aplicáveis, e os efeitos prospectivos visando o equilíbrio e a sobrevivência do sistema.

Sabe-se que no Brasil ainda temos dificuldade em fugir dos reducionismos do pensamento catalogador, baseado na hierarquia normativa e simplificado sob a forma piramidal.

A Constituição Federal está no grau mais elevado da hierarquia, à qual todas as demais normas devem-se adaptar. Em ordem decrescente, têm-se as leis complementares, 
as leis ordinárias, os decretos e os demais regulamentos e atos normativos inferiores. Nestes incluem-se as instruções, portarias e resoluções.

$\mathrm{Na}$ estrutura do princípio tripartite da separação de poderes, se três são, conceitualmente, as funções de Estado, uno e indivisível, ${ }^{14}$ na prática, é o Poder que deve ser exercido não apenas para aplicar a lei como também para concretizar, de um modo geral, os valores e princípios políticos compartilhados na sociedade.

Então, aplica-se e realiza-se o Direito mais que a lei propriamente dita. Nesse sentido, caberia à lei, como diretriz geral que contempla e procura acolher essa ordem de valores e princípios políticos, definir os parâmetros normativos e as estradas jurídicas a serem perfilhadas, e não detalhar e tecer minúcias quanto ao modo de trilhar tais caminhos e, ao administrador público, a instrumentalização da lei.

São esses aspectos que serão tratados no presente artigo, examinando-se as três categorias mais adotadas pela doutrina e pela jurisprudência para justificar ou contestar as normas editadas pelo Poder Executivo. A partir dessas reflexões, concluir-se-á pela ampliação da atual ordem hierárquica da clássica pirâmide normativa.

\section{A TESE DA DELEGAÇÃO NORMATIVA}

Diante da complexidade e a tecnicidade que notabilizam as sociedades contemporâneas, foi sendo reconhecida com o tempo, ou ao menos consentida tacitamente - de um modo ou de outro, ainda que contrariamente ao previsto na letra da Constituição Federal - alguma forma de delegação normativa do Legislativo a órgãos do Poder Executivo.

A crescente complexificação das matérias e a impossibilidade de o parlamento dar resposta pronta e conveniente a todas as exigências de um modelo de Estado de bem-estar conduziram a uma progressiva assunção de poderes normativos por parte do executivo, incluindo a permanente feitura de atos, com força de lei, cuja prática pelo executivo a Constituição configurava como tendo uma natureza excepcional, podendo falar-se, num primeiro momento, em tentativa de fraude à Constituição e hoje, atendendo à reiterada prática e à ausência de qualquer sancionamento judicial, será possível defender-se a formação de um costume constitucional contra constitutionem. ${ }^{15}$

Esse movimento parte da ideia de que devem existir normas expedidas pelo Poder Executivo para fazer face à necessidade de suprir, de modo célere e adequado, as lacunas que frustram, por ausência normativa, a consecução de interesses dos cidadãos.

Veja-se o pensamento de Diogo de Figueiredo Moreira Neto ${ }^{16}$ sobre a transição daquela fase racionalista que propugnava uma legalidade ortodoxa e totalmente avessa a qualquer tipo de delegação normativa para inaugurar, nas sociedades pluralistas e de massa, a fase de uma legalidade temperada, em que se admitia o instituto da delegação normativa, nos seguintes termos: 
Este princípio de reserva legal, que se constitui numa garantia individual fundamental, tem sido, por longa tradição, adotado nos ordenamentos constitucionais, ditando uma interpretação restritiva do princípio da separação de poderes, que assim prevaleceu durante um longo período de amadurecimento do Direito Público, passando por duas fases: a primeira, de absoluta inaceitação e, depois, da aceitação limitada da delegabilidade da função normativa [...] A lei, como conceito iluminista-racionalista, como produto do Estado formalmente manifestado pelos órgãos legislativos constitucionais, parece ter atingido seu zênite como instrumento regrador de condutas sociais. Com efeito, o pluralismo, ao multiplicar os centros de poder na sociedade, tornando-a policrática, fez despontar novas fontes normativas autônomas e semiautônomas que atuam com vantagem como sucedânea da norma legal. Por outro lado, a omnímoda submissão da sociedade a uma excessiva padronização e detalhamento de comportamentos por via legislativa, a pretexto de racionalizá-los e de impor critérios tidos como superiores, acaba paradoxalmente desservindo à ordem jurídica, não só por banalizá-la, como pelo desgaste que causa a babel provocada pelo incontrolável chorrilho legiferante a que se dedicam legisladores federais, estaduais e municipais de milhares de casas legislativas.

Nessa linha de considerações, surgiu em alguns países ${ }^{17}$ a teoria da "delegação legislativa" para a edição de normas pelo Poder Executivo.

O argumento utilizado é o de que o instituto revelava-se uma necessidade do Estado Moderno, um expediente atenuador e de cooperação entre os Poderes Legislativo e Executivo, sempre reservada a via do Judiciário para discutir a juridicidade de todo e qualquer ato normativo.

Delegação legislativa, no sentido ora focalizado, ${ }^{18}$ é a transferência da função normativa atribuída originária e constitucionalmente ao Poder Legislativo a órgãos ou agentes especializados do próprio Legislativo ou integrantes dos demais Poderes do Estado. Seria assim o repasse da competência constitucional para a edição de normas jurídicas por meio da desconcentração de competência institucional do Estado (a competência legiferante), isso em virtude da pletora de atribuições assumidas pelo Poder Executivo que reduziu por toda parte a suficiência do Poder Legislativo para regrar juridicamente a miríade de aspectos e complexidades das dinâmicas relações sociais.

De fato, para que a delegação normativa possa coadunar-se com os parâmetros da juridicidade, é imperioso que estejam presentes os seguintes requisitos: (1) previsão na Constituição ou na lei formal; (2) ato expresso de delegação da competência normativa; (3) transferência da função legiferante ordinária ou a órgão, ou a agente 
de outro Poder do Estado; (4) limitações fixadas pelo Poder delegante; (5) possibilidade de revogação e indelegabilidade da delegação; (6) preservação da idêntica competência delegada pelo Poder delegante; (7) controle político do órgão delegante sobre a legislação delegada; (8) controle jurisdicional sobre a observância pela autoridade delegada das condições e limites estabelecidos pelo Poder Legislativo no ato da delegação. ${ }^{19}$

Duas são as espécies de delegação: a nominada, que decorre do texto constitucional de 1988 (art. 68), e a inominada, que advém de norma abertura ou interpretação sistemática de dispositivos da Constituição Federal ou do ordenamento infraconstitucional. A polêmica que envolve o tema se limita à segunda espécie - a delegação inominada - pois a primeira, como dito, tem tratamento constitucional expresso. A delegação inominada compreende as variadas experiências de atribuição de função normativa sem a previsão constitucional expressa, e que, costumeiramente, se perfazem no curso da estruturação de determinado órgão ou entidade da administração direta ou indireta. Esses entes recebem, para além de suas funções tipicamente executivas, competência materialmente normativa para disciplinar, na mais das vezes, por via de resolução ou instrução normativa, o setor ou a atividade abrangida pelo serviço público assim descentralizado. Tais delegações decorrem ou devem decorrer de uma outorga legal, e desde que se atenham e sejam exercidas nos limites dos poderes que foram transferidos (intra legem), são compatíveis com a ordem jurídica, isto é, não são atentatórias do Direito, antes, como já mencionado, decorrem até de uma exigência das necessidades cotidianas. ${ }^{20}$

Com a promulgação da Constituição Federal de 1988 não foi positivada, expressamente, a indelegabilidade normativa. A matéria constou do art. 25 dos Atos das Disposições Constitucionais Transitórias ${ }^{21}$ para revogar as delegações anteriormente outorgadas no prazo de 180 dias, renováveis.

Com esse artigo, teriam sido revogados todos os dispositivos legais que atribuíssem ou delegassem a órgão do Poder Executivo competência assinalada pela Constituição ao Congresso Nacional, especialmente no que tange à ação normativa? Além disso, a questão, a saber, envolve uma segunda indagação: com a nova Carta Política, estaria definitivamente sepultada qualquer possibilidade de delegação legislativa inominada (a que não se dê por meio de lei delegada constante do art. 68 da CF)?

$\mathrm{Na}$ prática, nem a primeira, nem a segunda pergunta podem ser respondidas afirmativamente.

Estão aí, para comprovar essa assertiva, as inúmeras normas (Resoluções, Portarias, etc.) expedidas por Conselhos, Institutos, Fundações, a exemplo do Conselho Nacional de Meio Ambiente (Conama), Conselho Nacional de Trânsito (Contran), Receita Federal do Brasil, Conselho Monetário Nacional (CMN), dentre outros.

Ademais disso, vale conferir o debate ocorrido no julgamento do Recurso Extraordinário n. 286.963-5, Minas Gerais, em que foi relator o ministro Sepúlveda 
Pertence. Nesse aresto, houve um prolongado debate sobre a validade da Lei n. 4595/64 na parte em que outorga poderes ao Conselho Monetário Nacional para dispor sobre as taxas de juros bancários por meio de normas editadas após o período de 180 (cento e oitenta) dias assinalado naquele artigo (art. 25 da ADCT).

Se com relação aos entes integrantes da linha hierárquica do chefe do Poder Executivo a questão não foi resolvida, quiçá no que se refere às entidades reguladoras independentes (isto é, não integrantes da linha de subordinação à chefia do Poder Executivo).

\section{A TESE DO REGULAMENTO AUTÔNOMO}

Segundo Oswaldo Aranha Bandeira de Mello, regulamentar é desenvolver os preceitos constantes da lei, expressos ou implícitos, dentro da órbita por ela circunscrita, isto é, as diretrizes, em pormenor, por ela determinadas. ${ }^{22}$ Nas palavras de Bonifácio Fortes,

... visa o regulamento desdobrar, ampliar, detalhadamente, o conteúdo da Lei.

Com este propósito pode o regulamento dispor sobre o que a lei não cogitou, sem, no entanto, contrariar o seu espírito, pois a lei não pode prever todas as situações e minúcias. A lei dispõe apenas sobre a substância e os princípios, cabendo ao Executivo criar condições propícias à sua execução de tal forma que a sua efetivação se realize. ${ }^{23}$

O debate acerca das funções normativas detidas pelas entidades reguladoras independentes volta-se, ainda, à competência privativa do chefe do Poder Executivo para expedir regulamentos.

Sobre essa questão, Lúcia Valle Figueiredo, ${ }^{24}$ ao afirmar que as determinações normativas oriundas das entidades reguladoras devem-se limitar a aspectos técnicos estritamente pertinentes a usuários, sugere que a grande dúvida e celeuma que o tema traz envolve o conceito de regulação.

Desse modo, a autora indaga se diferem regulação de regulamentação para, a seguir, concluir: "Se regulação for diferente de regulamentação, não haveria qualquer impedimento constitucional, porque às agências reguladoras estaria reservada, dentro daquela margem de liberdade técnica da interpretação, a fixação das condições de atuação dos setores por ela fiscalizados”. 25

Gomes Canotilho também identifica essa polêmica:

A função de regulação (e de controle) de um determinado sector (mercado de valores mobiliários, comunicação social, energia, água e resíduos) atribuídas por lei a certas entidades independentes fará delas essencialmente autoridades reguladoras que estabelecem as regras e controlam a aplicação 
das normas. Fixar "regras reguladoras" corresponde, tendencialmente, a regulamentar matérias no figurino clássico da administração pública. ${ }^{26}$

Como dito, há necessidade de que o Poder Executivo tenha, em muitas situações, de atuar sem uma conduta totalmente predeterminada por uma regra, sempre, porém, balizado por certos limites jurídicos. Nesse contexto, a doutrina publicista, desde remota data, trilha o caminho do poder regulamentar para a consecução de tal desiderato, fundamentando, nessa linha de pensamento, a impossibilidade da "simples aplicação mecânica da lei" 27 pelo administrador público sem qualquer inovação.

Por sua vez, além dos regulamentos destinarem-se a dar fiel execução à lei, ${ }^{28} \mathrm{e}$, nesse caso, estarem a ela vinculados, sustenta-se, doutrinariamente, a existência de regulamentos autônomos ${ }^{29}$ na materialização da função normativa. ${ }^{30}$

Eros Grau afirma que regulamentos autônomos são os que, decorrendo de atribuição do exercício de função normativa implícita no texto constitucional, importam o exercício daquela função pelo Executivo para o fim de viabilizar a atuação, dele, no desenvolvimento de função administrativa de sua competência; envolvem, quando necessário, inclusive a criação de obrigação de fazer ou deixar de fazer alguma coisa. ${ }^{31}$

Castro $^{32}$ sustenta que o regulamento autônomo - ainda que não tenha poderes derrogatórios de normas legais, em sentido formal, isto é, não prospere contra legem - , cria direito novo, sem que se fundamente em lei que esteja regulando ou que lhe delegue competência para outras disciplinas intra legem, porque se alicerça na competência discricionária da administração, criando direito novo praeter legem. Tratam-se de atos administrativos normativos, não condicionados à lei ordinária, pelo qual órgãos e entidades do Poder Executivo editam normas com arrimo em suposta reserva regulamentar autônoma, que expressam genuíno poder legislativo governamental. Cuida-se, enfim, de normas editadas com base na competência discricionária do Executivo e destinadas a disciplinar setores não ocupados pela legislação, mas para os quais não subsiste reserva legal por imperativo da Constituição.

Segundo Castro, a jurisprudência liberal e tradicionalista, mormente aquela que floresceu à sombra da Constituição de 1946, também repudia a utilização do regulamento para a criação de direitos e obrigações independentes da lei formal. Contudo, essa orientação tem sido minimizada através dos tempos, conforme deixa entrever o enunciado da Súmula 186 do Supremo Tribunal Federal. A tendência hoje, portanto, em sintonia com os reclamos da moderna administração pública, é de se permitir o exercício do poder regulamentar autônomo, desde que, segundo esclarece com propriedade Diogenes Gasparini, calcado "numa expressa disposição da Lei Maior ou no costume constitucional, ou, ainda, na construção do próprio texto". 33 Isto é, deve traduzir-se no fiel detalhamento das condições de realização de direitos, deveres e 
demais disposições normativas previstas, explícita ou implicitamente, na lei que lhe confere fundamento de validade. $\mathrm{O}$ argumento presente é de que há certas hipóteses em que não é possível conferir fiel regulamentação à lei sem dispor sobre certos aspectos que estão implícitos na ratio essendi daquela, e sem cuja normatização, por inteiro, e em todos seus aspectos, sobretudo os de ordem técnica, não é possível conferir-lhe fiel executoriedade.

Com efeito, o Supremo Tribunal Federal vem admitindo a teoria do regulamento autônomo. Confira-se no acórdão proferido nos autos da Ação Direta de Inconstitucionalidade 2950-9, em que foi relator o ministro Eros Grau. No caso, foi apreciada a constitucionalidade de Decreto da governadora do Estado do Rio de Janeiro, que autorizou a Loteria do Estado do Rio de Janeiro (Loterj) a explorar bingos.

Por outro lado, colhem-se arestos do Superior Tribunal de Justiça, contrariamente à tese do Regulamento Autônomo. Vale trazer dois acórdãos, em que foi relator o ministro Luiz Fux, nessa ordem de conviç̧ão.

No primeiro (REsp 778338/DF), o aresto foi assim ementado: ADMINISTRATIVO E PROCESSUAL CIVIL. RECURSO ESPECIAL. VIOLAÇÃO A DECRETO NÃO CONFIGURADA. CONSELHO FEDERAL DE MEDICINA VETERINÁRIA. EXAME NACIONAL DE CERTIFICAÇÃO PROFISSIONAL. DESCABIMENTO. ACÓRDÃO CALCADO NO PRINCÍPIO DA LEGALIDADE. 1. [...] 3. A imposição do registro não pode ser inaugurada por Resolução, haja vista que o ato administrativo de caráter normativo subordina-se ao ordenamento jurídico hierarquicamente superior, in casu, à lei e à Constituição Federal, não sendo admissível que o poder regulamentar extrapole seus limites, ensejando a edição dos chamados "regulamentos autônomos", vedados em nosso ordenamento jurídico.

O segundo (RMS 16585/RJ), seguiu com a seguinte ementa: ADMINISTRATIVO. INSTALAÇÃO DE LACRES ELETRÔNICOS NOS TANQUES DOS POSTOS REVENDEDORES DE COMBUSTÍVEIS. CONSTITUCIONALIDADE DA LEI 3438/2000. ADIN 2334-9/2003. RESPONSABILIDADE EXCLUSIVA DAS DISTRIBUIDORAS. INEXISTÊNCIA DE SOLIDARIEDADE PASSIVA DOS POSTOS FORNECEDORES. ILEGALIDADE DA MULTA. RECURSO PROVIDO. 4. O Decreto 29.043/01, que acrescentou o art. 10A ao anterior diploma supratranscrito [que] não previu a referida responsabilização solidária não poderia prevalecer. Isto porque, se assim o fizesse, extrapolaria os limites traçados pela Lei regulamentada, alterando seu conteúdo e alcance, além de contrariar o sistema que repudia os regulamentos autônomos.

\section{A TESE dA DESLEGAlizAÇÃo}

Outra teoria sustentada para conformação da atuação do Poder Executivo é a da deslegalização de matérias do Legislativo para entidades do Executivo. O tema já foi 
agitado em sede doutrinária e pretoriana notadamente em temas cuja positivação pelas casas legislativas apresenta-se inviável.

Por exemplo, o Plenário do Supremo Tribunal Federal, ao julgar o Recurso Extraordinário n. 140.669-1/PE, relator o eminente ministro Ilmar Galvão, apreciando a constitucionalidade de leis ainda editadas sob a égide da Constituição anterior, já teve o ensejo de examinar e acolher a tese da deslegalização, desde que a norma observe não só os parâmetros de legalidade que lhe foram traçados, mas, também, em um sentido mais lato, os padrões de juridicidade delineados em determinado sistema jurídico, e desde que não se trate de matéria sujeita à reserva de lei.

Note-se que ali se estava diante, inclusive, de matéria tributária (embora não se tratasse de ato normativo definidor de tributo ou de elemento essencial deste, mas de elemento secundário). Contudo, mesmo assim foi reconhecida a juridicidade de transferência normativa de lei para o Executivo, para que este, por meio de portaria, alterasse o prazo de recolhimento do tributo ali em questão.

Entendeu-se, então, que a fixação de prazo para o recolhimento de tributo não é matéria submetida à reserva legal. Logo, poderia ser objeto de "deslegalização". É o que se colhe da ementa do acórdão, in verbis:

Tributário. IPI. Art. 66 da Lei n. 7.450/85, que autorizou o ministro da Fazenda a fixar prazo de recolhimento do IPI, e portaria n. 266/88/MF, pela qual dito prazo foi fixado pela mencionada autoridade. Elemento do tributo em apreço que, conquanto não submetido pela Constituição ao princípio da reserva legal, fora legalizado pela Lei n. 4.502/64 e assim permaneceu até a edição da Lei n. 7.450/85, que, no art. 66, o deslegalizou, permitindo que sua fixação ou alteração se processasse por meio da legislação tributária (CTN, art. 160), expressão que compreende não apenas as leis, mas também os decretos e as normas complementares (CTN, art. 96).

Digna de nota também é a seguinte passagem constante do corpo do acórdão, nos seguintes termos:

O juiz Tift emitiu um voto brilhante dizendo que a indelegabilidade que tem origem constitucional - não pode jamais ser encarada em termos absolutos. Acrescentou que pode a lei estabelecer, inclusive em matéria tributária, atribuições ao Poder Executivo - autoridade administrativa. Para que isso aconteça é preciso que haja autorização legal e que o exercício desse poder se faça dentro dos limites razoáveis. A deslegalização encontra limites constitucionais nas matérias constitucionalmente reservadas à lei. Sempre que exista reserva material de lei, a lei ou a decreto-lei (no caso de autorização legislativa) não poderão limitar-se 
a entregar aos regulamentos a disciplina jurídica da matéria constitucionalmente reservada à lei.

García de Enterría ${ }^{34}$ comenta o instituto francês de deslegalização de matérias pelo Legislativo ao Executivo:

Desde la famosa Ley de 17 de agosto de 1948 se sortea de la técnica de la deslegalización o rebajamiento del rango normativo de la regulación de determinadas materias, que quedan así entregadas al poder reglamentario (matières relevant de la compétence du pouvoir règlementaire, dice expresamente esa Ley). Esta práctica, que se repetirá cada vez con mayor osadía, recordando ya casi exactamente la técnica de los anteriores Decretos-Leyes [...], va a ser sancionada por la autoridad del Consejo de Estado, consultado especialmente por el Gobierno sobre su compatibilidad con la Constitución.

A ideia dessa teoria, portanto, é que a normatização executiva pode ser legitimada e conformada ao contexto jurídico-constitucional brasileiro por meio da deslegalização de matérias, a conviver com as regras constitucionais e com a primeira fonte normativa ordinária: a lei.

Segundo Aragão, a lei não precisa preestabelecer os elementos das relações jurídicas a serem formadas. Não é necessário que ela tenha de chegar a fixar os direitos e as obrigações que teriam apenas a forma de seu mero exercício definida pelos regulamentos necessários à "mera" execução. ${ }^{35}$

A deslegalização não envolve a atribuição de uma discricionariedade diferenciada (especialmente a suposta "discricionariedade técnica") ${ }^{36}$, pois não se trata de atuar sob o manto "intocável” da conveniência e oportunidade discricionária. Decorre de uma ampliação (e evolução) das fontes normativas necessárias não só ao atingimento do fim público, em que é necessária a prevenção e mediação do caso concreto, como, notadamente, para considerar as "consequências específicas sobre o setor regulado". 37

Quando se cogita a deslegalização para a compatibilização da escolha executiva ao atual contexto jurídico-constitucional brasileiro, não se pretende sustentar a retirada da base legalitária para a atuação das entidades administrativas na regulação de atividades econômicas e setores sensíveis à sociedade. O que a doutrina sustenta é a manutenção do "monopólio da política legislativa"38 nas mãos do Legislativo e a “autorização deste”, 39 prevista na norma primária, para que entes descentralizados do poder público possam estruturar a "moldura normativa", ${ }^{40}$ o marco regulatório de determinado subsistema especializado, sem estar atrelado às situações previstas anteriormente pela lei.

Para Paulo Otero, ${ }^{41}$ a deslegalização torna-se um processo de reforço da escolha administrativa gerando um correlativo enfraquecimento da tradicional esfera de 
intervenção vinculativa do poder legislativo. Torna a legalidade administrativa mais dócil ou adptável aos propósitos da administração pública, encurtando, assim, os espaços de heterovinculação da legalidade.

Assim, deslegalizar significa não estarem perfeitamente indicados na lei os meios para atuação dos agentes estatais responsáveis pela regulação de subsistemas sensíveis ao equilíbrio das ambivalências sociais.

\section{CONCLUSÃO}

Após examinarmos a teoria da delegação legislativa inominada, a teoria do regulamento autônomo e a teoria da deslegalização, pode-se, então, trazer conclusões sobre essas teorias vis-à-vis as normas regulatórias expedidas por autoridades reguladoras independentes.

Se, de um lado, parte da interpretação doutrinária refere-se à atuação normativa das entidades reguladoras independentes como sendo uma forma de "delegação", parece certo afastar esse rótulo ao perfilhar o entendimento de que não se trata da transferência de funções legislativas para entidades do Poder Executivo. ${ }^{42}$ Nestes casos, há execução, pela administração pública, da Lei, que, contudo, deixou de estabelecer maiores detalhes sobre a matéria legislada, fixando apenas standards e finalidades gerais. ${ }^{43}$

As normas reguladoras são opções administrativas, também abstratas, embora formuladas com maior densidade técnica, visando à incidência sobre específicas relações interprivadas críticas que foram previamente deslegalizadas, voltadas, assim, não mais a aplicar uma regra legislativa predefinida, mas a equilibrar interesses e valores em concorrência por meio de uma nova regra a ser administrativamente definida pelo método da ponderação. ${ }^{44}$

Entende-se, dessa forma, que só há delegação quando se faculta ao regulamento a inovação absoluta como se lei fosse - o que, no caso, parece não ocorrer. Vale dizer, só se delega aquilo que se tem: a nova categoria de escolha administrativa batizada de "regulação" é mais do que simplesmente baixar regras normativas.

Pelas normas regulatórias permite-se o exercício da capacidade técnica para dispor com maior densidade sobre as matérias necessárias para equilibrar o subsistema regulado, diversamente das leis que, editadas pelo Poder Legislativo, assumem caráter genérico, distante do cidadão e sem concretude; e dos regulamentos elaborados pelo chefe do Poder Executivo em gabinetes herméticos à participação e controle da sociedade. ${ }^{45}$

Sobre o enquadramento na teoria do Regulamento Autônomo, nos parece que conduz o tema para o sítio da discricionariedade, o conhecido "cheque em branco" que se sustenta em bases axiológicas próprias do administrador público, impermeável à atuação dos regulados e da sociedade em geral. E a categoria de escolha administrativa discricionária não é o melhor caminho a ser trilhado. ${ }^{46}$ 
A doutrina vem sustentando que "aos poucos, o caráter totalmente livre invocado na ideia originária de discricionariedade vai se atenuando", ${ }^{47}$ o que requer uma visão diversa do atual quadro que ainda se mantém ${ }^{48}$ na interpretação doutrinária e pretoriana brasileira.

O momento por que passa a humanidade requer a atuação estatal por meio de escolhas administrativas que, para além de uma suposta prevalência do interesse público, efetivamente sopesem interesses, examinem custos e benefícios à luz de questões técnicas e científicas, atuem nos riscos ${ }^{49}$ à sociedade pluriclasse e a cada cidadão, isto é, de acordo com a realidade.

Segundo a nova compreensão do direito administrativo no constitucionalismo atual, e de modo aparentemente paradoxal, se de um lado há uma "tendência a reduzir margem", 50 um "decréscimo" 51 e mesmo "limitação" 52 da discricionariedade na atuação do administrador público, uma verdadeira "restrição à dimensão constitucional e democrática" 53 e "mayor objetividad en la apreciación de los elementos", 54 importando "redefini-la, de acordo com os postulados do constitucionalismo póspositivista, a partir da noção do princípio da juridicidade"; 55 de outro lado, a complexidade cotidiana, que conduz ao permanente ambiente de ambivalência, impõe uma maior maleabilidade legiferante, atuação executiva e, portanto, espaços para a escolha administrativa. ${ }^{56}$

Esses fatores trazem mais imprevisibilidade à atuação executiva reguladora, afetando direitos fundamentais dos cidadãos.

Como se vê, tanto a teoria da delegação legislativa inominada quanto a teoria dos regulamentos autônomos não trazem respostas seguras para o enfrentamento da regulação normativa por meio das entidades reguladoras, por não se enquadrarem na modalidade piramidal, tradicional, de regulamentação secundária. ${ }^{57}$

Quanto à teoria da deslegalização, ela representa, a nosso sentir, um avanço na possibilidade de se acompanhar a necessária abertura e o crescimento dos espaços para a atuação do Poder Executivo na busca de soluções para o equilíbrio cíclico dos subsistemas e do exercício legítimo de políticas distributivas, com a redução da escolha discricionária, e inconclusivos debates acerca da impossibilidade ou limitação da sindicância dessas escolhas pelo Poder Judiciário.

Nessa senda, a deslegalização pode ocorrer pela exclusão legal de um comportamento a qualquer tipo de regra ou pela substituição do referencial normativo, indicando a nova fonte regradora; mas sempre com vistas à maior efetividade (e, não, transferência de competência, desprezo ou inexistência) da norma legalitária. ${ }^{58}$

Com efeito, no que tange às entidades reguladoras estas não recebem competências do Legislativo para formular normas abertas conformadas por aspectos políticos; por isso, e considerando ser "extremamente difícil submetê-las a uma ordem hierárquica definida", ${ }^{59}$ devem merecer um novo enquadramento na clássica pirâmide normativa ${ }^{60}$ prevista no vigente texto constitucional brasileiro. 
Daí que a missão das entidades reguladoras, como pré-intérpretes da Constituição ${ }^{61}$ mediante um trabalho exegético que procure encontrar, na "autorreferência do subsistema”, uma solução de concordância prática entre as normas constitucionais em tese aplicáveis a um determinado caso concreto submetido à regulação é fugir dos reducionismos do pensamento catalogador da hierarquia normativa e simplificado sob a forma piramidal. ${ }^{62}$

Com isso, editar atos normativos regulatórios por via da deslegalização representa a materialização de escolhas que busquem confrontar o problema a ser solucionado em face da Constituição e os bens e valores jurídicos que ali estariam conflitando, estabelecendo-se qual ou quais desses valores em conflito deverá prevalecer.

Desse modo, não parece haver dúvidas de que as normas editadas por entidades reguladoras devem obedecer aos preceitos legais - standards 63 -, pois a administração pública não tem um poder normativo incondicional e geral, como ocorre com o Poder Legislativo. ${ }^{64}$ Entretanto, não se pode enquadrar essas normas como sendo delegação inominada ou função regulamentar da lei, de competência do presidente da República e de outros entes, pois, em termos de regulação de atividades econômicas, a lei não consegue tudo prever.

A polêmica acerca da função normativa das entidades reguladoras se insere em uma discussão mais profunda, que envolve sua adaptação ao sistema tripartite oitocentista, subsumido no princípio da separação e do equilíbrio entre os poderes estatais, que impõe também uma revisão da hierarquia normativa.

Nessa ordem de convicções, é jurídico sustentar a constitucionalidade do exercício da função normativa "secundária" pelas entidades reguladoras por não se detectar, pela via da deslegalização, qualquer usurpação da função legiferante, de competência do Poder Legislativo, nem, tampouco, do poder regulamentar de atribuição precípua do chefe do Poder Executivo. 65

Só há delegação quando faculta-se ao regulamento a inovação da lei - o que não parece ser o caso. Também não é regulamento autônomo, pois a escolha regulatória não decorre de ato fora da lei. Pela escolha regulatória se permite o exercício da capacidade técnica das entidades descentralizadas para dispor com maior densidade sobre as matérias que lhe competem para equilibrar o subsistema regulado, diversamente das leis que, editadas pelo Poder Legislativo, assumem caráter genérico e sem concretude. 66

Resta dizer, "regular" abrange outros institutos muito mais densos do que a "regulamentação" de uma lei, seja de execução ou autônoma.

A função regulamentar de competência do chefe do Poder Executivo não é somente reproduzir a lei, analiticamente, mas ampliá-la e completá-la, segundo seu espírito e seu conteúdo, sobretudo nos aspectos que a própria lei, expressa ou implicitamente, outorga à esfera regulamentar. Por outro lado, a função regulatória (ou reguladora) visa a realizar o gerenciamento dos múltiplos e antinômicos interesses da 
sociedade, traduzindo-se "em restrições à autonomia privada para evitar que o exercício abusivo de certas prerrogativas ponha em risco a realização de outros valores”. 67

A regulamentação é cometida a chefes de Estado ou Governo, é uma função política, que visa a impor regras de caráter secundário em complementação às normas legais, com o objetivo de explicitá-las e dar-lhes execução. A regulação é uma função administrativa, que não decorre da prerrogativa do poder político, e, sim, da abertura da lei para que o agente regulador pondere, de forma neutra, os interesses concorrentes em conflitos setoriais, sejam eles potenciais ou efetivos. ${ }^{68}$

Por esses argumentos, a competência normativa exercida pelas entidades reguladoras, inserida no sistema de separação de poderes e considerando-se a proeminência da instituição legislativa para a positivação das regras jurídicas ("legalidade formal axiológica, legalidade material leve ou legalidade principiológica”), ${ }^{69}$ é inconfundível com o "poder regulamentar" primário, de competência do chefe do Poder Executivo. ${ }^{70}$

Diante do exposto, e considerando que entidades reguladoras editam normas que dificilmente podem ser submetidas a uma ordem hierárquica definida no modelo tradicional, normas essas que vêm sendo admitidas em quase a totalidade dos julgamentos proferidos sobre o tema pelo Superior Tribunal de Justiça, ${ }^{71}$ devem merecer um novo enquadramento na clássica pirâmide normativa, independentemente do nomen juris.

: ARTIGO APROVADO (30/06/2011) : RECEBIDO EM 04/04/2011

NOTAS

* Parejo Alfonso, Administrar y juzgar: dos funciones constitucionales distintas y complementarias, p. 31 .

1 Meilán Gil, Progreso tecnológico y servicios públicos, p. 127.

2 Cf. Sérgio Guerra, Discricionariedade e reflexividade: uma nova teoria sobre as escolhas administrativas, c. II.

3 Veja-se como devem ser os procedimentos para as delegações legislatitvas a teor do que dispõe o art. 68 da Constituição de 1988: As leis delegadas serão elaboradas pelo presidente da República, que deverá solicitar a delegação ao Congresso Nacional. $\S 1^{\circ}$ Não serão objeto de delegação os atos de competência exclusiva do Congresso Nacional, os de competência privativa da Câmara dos Deputados ou do Senado Federal, a matéria reservada à lei complementar, nem a legislação sobre: I - organização do Poder Judiciário e do Ministério Público, a carreira e a garantia de seus membros; II - nacionalidade, cidadania, direitos individuais, políticos e eleitorais; III - planos plurianuais, diretrizes orçamentárias e orçamentos. $\S 2^{\circ}$ A delegação ao presidente da República terá a forma de resolução do Congresso Nacional, que especificará seu conteúdo e os termos de seu exercício. $\S 3^{\circ}$ Se a resolução determinar a apreciação do projeto pelo Congresso Nacional, este a fará em votação única, vedada qualquer emenda. 
4 Nesse sentido, Alexandre Santos de Aragão e Patrícia Sampaio comentam a possibilidade e os limites da função normativa das agências reguladoras: "Deve ser compreendida à luz da finalidade do exercício da atividade administrativa, a qual reside no cumprimento das competências constitucional e legalmente consagradas às autoridades. Nessa perspectiva, entende-se a feição normativa do poder de polícia como instrumento legítimo de concretização desses objetivos. Não se trata, em qualquer hipótese, de autoridades administrativas exercendo competência legislativa ou quaselegislativa (no Brasil, a figura do regulamento autônomo mostra-se excepcional - art. 84, VI, da Constituição Federal), mas sim de atividade normativa inserida no bojo das competências administrativas do Estado e, por conseguinte, subordinada, sempre, à legalidade”. (Alexandre Santos de Aragão e Patrícia Sampaio, Omissão no exercício do poder normativo das agências e a concorrência desleal, in, Aragão, coord., O poder normativo das agências reguladoras, p. 547).

5 Maria Sylvia Zanella Di Pietro critica a função normativa exercida pelas entidades reguladoras: “A intenção de colocar tais atividades [serviços públicos] sob regime jurídico de direito privado vem sendo frustrada pela atividade regulatória exercida pelas agências, que acaba substituindo o direito administrativo criado por lei pelo direito administrativo criado por agências pretensamente independentes, na realidade muito mais autoritárias do que independentes" (Di Pietro, Privatização e o novo exercício de funções públicas por particulares, in, Moreira Neto, coord., Uma avaliação das tendências contemporâneas do direito administrativo, 2003, p. 434).

6 Segundo doutrina de Eros Grau, os chamados “regulamentos autorizados” (ou “autorizativos”), são aqueles que dispõem sobre matérias que, embora não cheguem a serem disciplinadas detalhadamente em lei formal, nela encontram seu fundamento de validade (Eros Grau, $O$ direito posto e o direito pressuposto, p. 252).

7 Também é expressão constante da doutrina de Grau (op. cit., p. 231).

8 Fabrício Motta denomina de "remissões normativas" os casos em que a lei "reenvia a um ato normativo inferior e posterior, a ser elaborado pela Administração, a regulação de certos elementos que complementam a ordenação estabelecida na própria lei” (Fabrício Motta, A função normativa da administração pública brasileira, p. 146).

9 Laubadère, Direito público econômico, p. 121.

10 Sob esse viés clássico do princípio da legalidade em cotejo com a atuação da Administração Pública, expõe Diogenes Gasparini: “O princípio da legalidade significa estar a Administração Pública, em toda a sua atividade, presa aos mandamentos da lei, deles não se podendo afastar, sob pena de invalidade do ato e responsabilidade de seu autor. Qualquer ação estatal sem o correspondente calço legal, ou que exceda ao âmbito demarcado pela lei, é injurídica e expõe-se à anulação" (Gasparini, Direito administrativo, p. 6).

11 Zagrebelsky adverte que até mesmo na França já existe um forte movimento para reduzir a força da lei. Consta que em 23 de agosto de 1985 o Conseil Constitutionnel decidiu que "la loi votée n'exprime la volonté générale que dans le respect de la Constitution” (Zagrebelsky, El derecho dúctil, derechos, justicia, p. 61).

12 Giddens, As consequências da modernidade, p. 45.

13 Marques Neto, Pensando o controle da atividade regulação estatal (in: Guerra, Temas de direito regulatório, p. 202.

14 Conforme leciona Clèmerson Merlin Cléve, o poder político é indivisível, teoricamente, porque seu titular é o povo que não o divide, senão que, em face da ação do Poder Constituinte, confere o exercício a diferentes órgãos encarregados de exercer distintas tarefas ou atividades, ou ainda diferentes funções. Ademais, o poder é indivisível por natureza. Não corresponde a uma coisa que a ela se possa aceder, algo com fim e começo, um objeto capaz de ser tomado, destruído ou multiplicado (Clève, Atividade legislativa do poder executivo, p. 30).

15 Otero, Legalidade e administração pública, p. 107-108.

16 Moreira Neto, Direito regulatório: a alternativa participativa e flexível para a administração pública de relações setoriais complexas no estado democrático, p. 118, 124.

17 Conforme anota Clèmerson Clève, os regulamentos delegados são aceitos, por exemplo, na Espanha e na Itália. No Brasil, em determinado momento e sob os influxos da doutrina norte americana, chegou-se a aceitar os regulamentos delegados sem maiores problemas (Clève, op. cit., p. 301). 
18 Cf. Castro, O congresso nacional e as delegações legislativas, p. 81-82.

19 Idem ibidem, p. 96.

20 Idem, ibidem, p. 96. Para o autor, desde que não se trate de matéria de reserva estrita de lei, como se dá com a definição de tributos ou de crimes, ou desde que não se trate de matéria de competência exclusiva do Congresso Nacional, da Câmara dos Deputados ou do Senado, não há se falar em ilegalidade ou em usurpação de poderes ou competências quando o administrador editar normas no exercício de um poder delegado. Pois há, ou deve haver, em toda delegação, um fundamento legal.

21 BRASIL. Constituição (1988). Disposições transitórias. Art. 25. Ficam revogados, a partir de cento e oitenta dias da promulgação da Constituição, sujeito este prazo a prorrogação por lei, todos os dispositivos legais que atribuam ou deleguem a órgão do Poder Executivo competência assinalada pela Constituição ao Congresso Nacional, especialmente no que tange a: $I$ - ação normativa.

22 Bandeira de Mello. Princípios gerais de direito administrativo, p. 314. Fortes, O poder regulamentar, Revista de Direito Administrativo, p. 39.

23 Fortes, op. cit., p. 39.

24 Figueiredo, Intervenção do estado no domínio econômico e breves considerações sobre as agências reguladoras, Revista de Direito Público da Economia, p. 267.

25 Idem, Ibidem, p. 267.

26 Canotilho. Direto Constitucional e teoria da Constituição, p. 818.

27 Binenbojm. Uma teoria do direito administrativo: direitos fundamentais, democracia e constitucionalização, p. 157.

28 Uma ampla sistematização dos regulamentos é feita por Caetano (Princípios fundamentais do direito administrativo, p. 79-85).

29 Cabral de Moncada, ao comentar o alcance inicial do princípio da legalidade, tendo como pano de fundo a relação de forças políticas entre o parlamento e o executivo monárquico, anota que o Poder Executivo dispunha de poder regulamentar autônomo em áreas que a lei não aparecesse, sob a veste de um poder regulamentar praeter-legem (Cabral de Moncada. Lei e regulamento, p. 73).

30 Sobre a questão dos regulamentos autônomos após a Emenda Constitucional 32/2001, ver Sérgio Varella Bruna (Agências reguladoras: poder normativo, consulta pública e revisão judicial, p. 89-91) e Binenbojm (op. cit., p. 160ss).

31 Grau, op. cit., p. 253.

32 Castro. O congresso nacional e as delegações legislativas, p. 121-125.

33 Idem, ibidem.

34 García de Enterría. Legislación delegada, potestad reglamentaria y control judicial, p. 106.

35 Aragão, Direito dos serviços públicos, p. 328. O autor enfatiza seu ponto de vista ao anotar: "Integramos a corrente daqueles para quem deve haver uma habilitação legal dos poderes da Administração Pública, sem que a lei precise entrar na matéria a ser regulada pela Administração" (grifo do autor).

36 Sobre o tema, ver Sérgio Guerra, Controle judicial dos atos regulatórios.

37 Cf. Moreira Neto, Mutações do direito público, p. 112.

38 Moreira Neto (Mutações do direito público, p. 262). O monopólio da política legislativa "vem a ser a competência para 
firmar princípios e baixar as normas gerais que deverão ser observadas pelas demais fontes intra-estatais”. Esse autor conclui seu raciocínio nos seguintes termos: "Persegue-se a norma que ganha em eficiência quanto ao conteúdo, porque mais próxima da realidade dos fatos, não só na aplicação como na elaboração: ela é mais técnica, menos vaga, de maior precisão, por isso, menos controvertida, e produz mais segurança jurídica aos jurisdicionados. Mas, ao mesmo tempo, ela ganha em eficiência quanto ao tempo, pois, dispensando os pesados e demorados processos legislativos nas casas parlamentares, ela é formulada na medida em que é necessária e, com a mesma celeridade pode ser revogada, alterada ou substituída" (Moreira Neto, Governo e governança em tempos de mundialização: reflexões à luz dos novos paradigmas do direito, Revista de Direito Administrativo. p. 46).

39 Como dito, Eros Grau utiliza a expressão “regulamentos autorizados" (Grau, op. cit., p. 252).

40 Torres, Tratado de direito constitucional financeiro e tributário, p. 507.

41 Otero, op. cit., p. 903.

42 Leila Cuéllar não compartilha do entendimento de que se trata de delegação de "poder normativo", na medida em que a delegação é sempre precária e excepcional. Caso a função normativa das entidades reguladoras derivasse de delegação, poderia, em tese, ser cassada essa competência, o que acarretaria extinção dos reguladores ou a frustração de sua natureza jurídica essencial, além do controle dessas funções ser inviável no sistema brasileiro (Cuéllar, As agências reguladoras e seu poder normativo, p. 116). No mesmo sentido, Bacellar Filho (O poder normativo dos entes reguladores e a participação dos cidadãos nesta atividade. Serviços públicos e direitos fundamentais: os desafios da regulação na experiência brasileira. Revista de Direito Administrativo, p. 160).

43 Aragão, Agências reguladoras e a evolução do direito administrativo econômico, p. 411.

44 Moreira Neto, Direito regulatório: a alternativa participativa e flexível para a administração pública de relações setoriais complexas no estado democrático, p. 114.

45 Nas palavras de Marcos Juruena Villela Souto o legislador não tem, necessariamente, o conhecimento técnico nem a proximidade dos fatos para editar a norma. Por isso, deve-se manter em um plano de generalidade para abrigar todas as situações inviabilizando que se adentre em detalhes. Ademais, as normas sobre o funcionamento do mercado tendem a ser normas técnicas, econômicas e financeiras, que mudam com a evolução tecnológica ou comercial. Se a lei cuidasse de cada detalhe, estaria constantemente desatualizada e provocaria a frequente necessidade de movimentação do Poder Legislativo. Conclusivamente, não há de se falar, em sede de normatização por reguladores independentes, de delegação do Poder Legislativo (Souto, Direito administrativo regulatório, p. 46).

46 Floriano Marques Neto chega a afirmar que, se fosse o caso, deveria ser, então, uma "nova discricionariedade". Segundo o autor, "a relação das agências reguladoras com o Direito se dá em face de uma nova legalidade: a lei define as metas principais e os contornos da atividade do órgão regulador, cometendo-lhe (nestes limites e sob controle do Judiciário e do próprio Legislativo) ampla margem de atuação. Atuação, esta, que segue um novo tipo de discricionariedade, pautado fundamentalmente pelos objetivos definidos na lei para serem implementados no setor regulado" (Marques Neto, A nova regulação estatal, in, Sundfeld, Direito administrativo econômico, p. 95).

47 Medauar, O direito administrativo em evolução, p. 195.

48 Vale trazer a advertência de Andreas Krell: "Há inúmeros juízes, promotores, procuradores e advogados que evitam uma discussão mais profunda e acabam aderindo à jurisprudência tradicional, que costuma usar uma classificação ultrapassada referente à discricionariedade administrativa, a qual não consegue fornecer soluções aos problemas" (Krell, A recepção das teorias alemãs sobre "conceitos jurídicos indeterminados" e o controle da discricionariedade no Brasil, p. 22 [grifo do autor]).

49 Nesse sentido, ver Krell, op. cit., p. 24.

50 García de Enterría. Democracia, jueces y controle de la administración, p. 135.

51 Medauar, op. cit., p. 230.

52 Barroso, Neoconstitucionalismo e constitucionalização do direito: o triunfo tardio do direito constitucional no Brasil, Revista da Emerj, p. 58. 
53 Justen Filho, Curso de direito administrativo, p. 14.

54 Madariaga Gutiérrez. Seguridad juridica y administración publica en el siglo XXI, p. 47.

55 Moraes, Controle jurisdicional da administração pública, p. 37.

56 Medauar: "A partir da segunda metade do século XX, com a dinâmica intervencionista, ampliaram-se as atribuições administrativas; um número crescente de decisões passou a afetar com mais amplitude direitos e interesses dos indivíduos. Ficava a impressão de que aumentara o campo de atuação livre da Administração" (Medauar, op. cit., p. 195).

57 Até porque o art. 84 da Constituição Federal dispõe que compete privativamente ao chefe do Poder Executivo o poder regulamentar.

58 Para Moreira Neto: “a alternativa participativa e flexível para a administração pública de relações setoriais complexas no estado democrático, p. 125. Nos termos do art. 48 da Constituição Federal: Cabe ao Congresso Nacional, com a sanção do presidente da República, não exigida esta para o especificado nos arts. 49, 51 e 52, dispor sobre todas as matérias de competência da União" (Moreira Neto, Direito regulatório: a alternativa participativa e flexível para a administração pública de relações setoriais complexas no estado democrático, p. 125).

59 Moreira Neto, Mutações do direito público, p. 40.

60 Há de se interpretar a questão da hierarquia à luz da teoria principiológica e dos valores, pois não se interpreta a lei em tiras, ou aos pedaços, muito menos a Constituição. Como observa Pietro Perlingieri, "pensar que se possa interpretar a norma singular 'na sua nudez linguística, como realidade solitária, irregular, errante', torna-se, de um ponto de vista lógico, uma petição de princípio e, de um ponto de vista axiológico, uma escolha não conforme à vigente hierarquia das fontes e dos valores" (Perlingieri, Perfis do direito civil: introdução ao direito civil constitucional, $\mathrm{p}$. $79,101)$.

61 Com predomínio do papel do julgador na "filtragem" constitucional, Peter Häberle apresentou uma teoria metodológica (1975) sob o ponto de vista epistemológico, voltada à sociedade aberta. A essência dessa metódica se atém à ampliação dos intérpretes da constituição, que inclui, além do Poder Judiciário, os cidadãos e os órgãos estatais, que passam a constituir força produtiva de interpretação, ao menos como pré-intérpretes (Vorinterpreten) do complexo normativo constitucional (Häberle, Hermenêutica constitucional: a sociedade aberta dos intérpretes da constituição: contribuição para a interpretação pluralista e "procedimental" da constituição). Gilmar Ferreira Mendes esclarece esse ponto na apresentação da obra de Häberle (op. cit., p. 9-10): “A norma não é uma decisão prévia, simples e acabada, tem-se, necessariamente, de indagar sobre os participantes no seu desenvolvimento funcional sobre as forças ativas da law in public action. A ampliação do círculo dos intérpretes constituiria para Häberle apenas uma consequência da necessidade de integração da realidade no processo de interpretação".

62 Aragão afirma: "O marco regulatório dos serviços públicos é constituído de elementos que não se relacionam apenas de maneira piramidal, havendo uma teia normativa disposta de forma flexível e inter-relacionável, que produz fluxos normativos multidirecionais, tanto de forma horizontal (normas de idêntica hierarquia), como vertical (normas de hierarquia diversa integrantes do mesmo setor normativo) e diagonalmente (normas de hierarquia diversa integrante de distintos setores normativos - ex.: resolução da Anatel versus lei consumerista)" (Aragão, Direito dos serviços públicos, p. 370 [grifo do autor]).

63 Cf. Cabral de Moncada, op. cit., p. 23.

64 Nesse sentido, tem-se a oportunidade de transcrever a manifestação de Celso Antônio Bandeira de Mello adotada contra a função normativa das agências reguladoras: "Reitera-se, pois, neste campo, a submissão total ou parcial dos atos administrativos à lei, ao encarecer-se que só por lei é possível restringir a liberdade econômica. [...] Esse último traço é que faz do regulamento, além de regra de menor força jurídica que a lei, norma dependente dela, pois forçosamente a pressupõe, sem o quê nada poderia dispor. No Direito pátrio, sem lei não haveria espaço jurídico para o regulamento" (Bandeira De Mello, Curso de direito administrativo, p. 315). Em complemento ao mesmo entendimento, Castro já se pronunciou sobre o tema, nos termos seguintes: "Assim, qualquer excesso do poder regulamentar, ou seja, qualquer desconformidade com a lei matriz v.g., a criação de obrigações ou supressão de direitos não previstos na lei regulamentada, importa em quebra da legalidade por abuso de poder, segundo a festejada lição de San Tiago Dantas, ao 
expor: 'sempre que um regulamento sobre matéria já disciplinada em lei, depara-se-nos o problema da perfeita adequação do regulamento ao texto da lei. E isso porque, sendo o regulamento uma simples particularização ou desenvolvimento da lei, a cujo espírito deve incondicional obediência, será ilegal e, portanto, inaplicável a disposição regulamentar que se puser em oposição ao comando do Legislativo, seja por contradizê-lo, seja por alargar ou reduzir o âmbito de suas palavras'. E mesmo a sua utilização para finalidades espúrias e não visadas pelo legislador do diploma subordinante pode deflagrar os mecanismos para a anulação por desvio de poder" (Castro, $O$ devido processo legal e a razoabilidade das leis na nova Constituição do Brasil, p. 125). Edmir Netto de Araújo, admitindo a edição de atos administrativos que significam o exercício do "poder normativo" das entidades reguladoras, denota que a função normativa das agências reguladoras, ou seja, a "função não regulamentar", vincula-se às normas legais pertinentes, sem inovar na ordem jurídica, e não é o de regulamentar leis e muito menos situações jurídicas autônomas (leis em sentido material) que criem direitos, deveres ou penalidades (Araújo, A aparente autonomia das agências reguladoras, in, Alexandre Moraes, org., Agências reguladoras, p. 41).

65 Diogo de Figueiredo Moreira Neto é taxativo: "Uma vez operada a deslegalização, a regulação, como produção normativa decorrente, não se confunde com as normas de regulamentação editadas pelo Poder Executivo e, muito menos, com as normas emanadas das Casas Legislativas” (Moreira Neto, Mutações do direito público, p. 400).

66 Alexandre Santos de Aragão adverte que muitas vezes a lei confere "poder regulamentar" a titular de órgão ou a entidade da Administração Pública distinta do chefe do Poder Executivo. O autor se vale da expressão cunhada por San Tiago Dantas, "descentralização do poder normativo do Executivo" para órgãos ou entidades tecnicamente mais aparelhados. Por essa descentralização o poder de estatuir normas jurídicas inferiores e subordinadas à lei, mas que nem por isso deixam de reger coercitivamente as relações sociais, é uma atribuição constitucional do presidente da República, mas a própria lei pode conferi-la, em assuntos determinados, a um órgão da Administração pública ou a uma dessas entidades autônomas que são as autarquias (Aragão, Agências reguladoras e a evolução do direito administrativo econômico, p. 381).

67 Justen Filho, O direito das agências reguladoras independentes, p. 556.

68 Moreira Neto, Direito regulatório: a alternativa participativa e flexível para a administração pública de relações setoriais complexas no estado democrático, p. 132-133. Nesse mesmo sentido, Marcos Juruena Villela Souto afirma que enquanto a regulação é técnica, a regulamentação é política, havendo legitimidade eleitoral para tanto. $\mathrm{O}$ mesmo não ocorre na regulação, que se limita a implementar a decisão política. A regulação atende a interesses coletivos (setoriais), enquanto que a regulamentação a interesses públicos, gerais (Moreira Neto, Direito administrativo regulatório, p. 233).

69 Aragão, Direito dos serviços públicos, p. 335.

70 Em igual pensamento, Sebastião de Botto Barros Tojal expõe que pelas competências conferidas às agências reguladoras estas projetam as iniciativas do Poder Público para o futuro, à medida que dizem respeito a objetivos, diretrizes, metas a serem traçadas com vista em consolidar o processo de intervenção estatal. Destaca que essas funções são diversas do papel exercido pelo regulamento administrativo, cuja utilidade consiste, fundamentalmente, em complementar a lei, facilitar a aplicação da lei, em suma, torná-la útil, facilitando sua implementação (Tojal, Controle judicial da atividade normativa das agências reguladoras, in, Moraes, Agências reguladoras, p. 161).

71 Tome-se como exemplo o aresto a seguir: LIMINAR E TELEFONIA. SERVIÇO PRÉ-PAGO. DEFESA AO CONSUMIDOR. LEGITIMAÇÃO DO MINISTÉRIO PÚBLICO. RECURSO ESPECIAL ADMITIDO. CAUTELAR E EFEITO SUSPENSIVO. FUMUS BONI IURIS E PERICULUM IN MORA PRESENTES. ATUAÇÃO CONFORME ATO DA AGÊNCIA REGULADORA. Vigente ato normativo da Agência Reguladora cujo escopo é regular o segmento, não podem os estabelecimentos regulados absorverem danos e punições pelo fato do cumprimento das regras maiores, posto engendrarem exercício regular do direito. modificação ex abrupto dessas regras da Agência Reguladora por tutela provisória em liminar concedida em ação, acarreta periculum in mora, mercê de o fumus boni iuris repousar no cumprimento do ato da Agência. Deveras, somente a ausência de nulificação específica do ato da Agência autoriza o Judiciário e intervir no segmento, sob pena de invadir seara administrativa estranha ao Poder Judiciário. (Sérgio Guerra, Controle Judicial dos Atos Regulatórios, p. 355, 369). Impossibilidade de atendimento técnico da decisão liminar, que configurou para o relator periculum in mora inverso, máxime porque a adoção da providência contrária ao ato da ANATEL (art. 55 da Resolução 316/2002, e itens 4.6 e 4.6.1, da Norma 03 $\square$ 98). MINISTRO LUIZ FUX MARÇO/2006. STJ AGRG na MC 10443-PB. 


\section{REFERÊNCIAS BIBLIOGRÁFICAS}

ARAGÃO, Alexandre Santos de. Agências reguladoras e a evolução do direito administrativo econômico. Rio de Janeiro: Forense, 2002.

Direito dos serviços públicos. Rio de Janeiro: Forense, 2007.

ARAGÃO, Alexandre Santos de; SAMPAIO, Patrícia Regina Pinheiro. Omissão no exercício do poder normativo das agências e a concorrência desleal. In: ARAGÃO, Alexandre Santos de. (Coord.) O poder normativo das agências reguladoras. Rio de Janeiro: Forense, 2006.

ARAÚJO, Edmir Netto de. A aparente autonomia das agências reguladoras. In: MORAES, Alexandre de. (Org.) Agências reguladoras. São Paulo: Atlas, 2002.

BACELLAR FILHO, Romeu Felipe. O poder normativo dos entes reguladores e a participação dos cidadãos nesta atividade. Serviços públicos e direitos fundamentais: os desafios da regulação na experiência brasileira. In Revista de Direito Administrativo, Rio de Janeiro, v. 230, out/dez 2002.

BANDEIRA DE MELLO, Celso Antônio. Curso de direito administrativo. 21. ed., rev. e atual. São Paulo: Malheiros, 2006.

. Discricionariedade e controle jurisdicional. 2. ed. São Paulo: Malheiros, 2001.

. Princípios gerais de direito administrativo. Rio de Janeiro: Forense, 1969.

BARROSO, Luís Roberto. Neoconstitucionalismo e constitucionalização do direito: o triunfo tardio do direito constitucional no Brasil. Revista da Emerj, Rio de Janeiro, v. 9, n. 33, p. 43-92, 2006.

BINENBOJM, Gustavo. Uma teoria do direito administrativo: direitos fundamentais, democracia e constitucionalização. Rio de Janeiro: Renovar, 2006.

BONAVIDES, Paulo. Curso de direito constitucional. 12 ed. São Paulo: Malheiros, 2002.

BRUNA, Sérgio Varella. Agências reguladoras: poder normativo, consulta pública e revisão judicial. São Paulo: Revista dos Tribunais, 2003.

CABRAL DE MONCADA, Luis S. Lei e regulamento. Coimbra: Coimbra Ed., 2002.

CAETANO, Marcello. Princípios fundamentais do direito administrativo. Reimpressão da edição brasileira de 1977, 2. reimp.o portuguesa. Coimbra: Almedina, 2003.

CANOTILHO, José Joaquim Gomes. Direto Constitucional e teoria da Constituição. 4. ed. Coimbra: Almedina, 2000. CASTRO, Carlos Roberto de Siqueira. O congresso nacional e as delegações legislativas. Rio de Janeiro: Forense, 1986.

O devido processo legal e a razoabilidade das leis na nova Constituição do Brasil. 2. ed. Rio de Janeiro:

Forense, 1989.

CLÈVE, Clèmerson Merlin. Atividade legislativa do poder executivo. 2. ed. São Paulo: Revista dos Tribunais, 2000. CORDEIRO, Antonio Menezes. Introdução. In: CANARIS, Claus-Wilhelm. Pensamento sistemático e conceito de sistema na ciência do direito. Lisboa: Fundação Calouste Gulbenkian, 1996.

CUÉLLAR, Leila. As agências reguladoras e seu poder normativo. São Paulo: Dialética, 2001.

DI PIETRO, Maria Sylvia Zanella. Privatização e o novo exercício de funções públicas por particulares. In:

MOREIRA NETO, Diogo de Figueiredo. (Coord.) Uma avaliação das tendências contemporâneas do direito

administrativo. Rio de Janeiro: Renovar, 2003.

FIGUEIREDO, Lúcia Valle. Intervenção do estado no domínio econômico e breves considerações sobre as agências reguladoras. Revista de Direito Público da Economia - RDPE, Belo Horizonte, n. 2, abr./jun. 2003.

FORTES, Bonifácio. O poder regulamentar. Revista de Direito Administrativo, Rio de Janeiro, jul./set. 1961.

GARCÍA DE ENTERRÍA, Eduardo. Democracia, jueces y controle de la administración. 5. ed. reimpr. Madrid: Civitas, 2005.

Legislación delegada, potestad reglamentaria y control judicial. 3. ed. Madrid: Civitas, 1998.

GASPARINI, Diogenes. Direito administrativo. 11. ed. São Paulo: Saraiva, 2006.

GIDDENS, Anthony. As consequências da modernidade. Tradução de Raul Fiker. São Paulo: Ed. Unesp, 1991. [Título original em inglês: The consequences of modernity.]

GRAU, Eros Roberto. O direito posto e o direito pressuposto. São Paulo: Malheiros, 2002.

GUERRA, Sérgio. Controle judicial dos atos regulatórios. Rio de Janeiro: Lumen Juris, 2005.

. Discricionariedade e reflexividade: uma nova teoria sobre as escolhas administrativas. Belo Horizonte: Forum, 2008.

HÄBERLE, Peter. Hermenêutica constitucional: a sociedade aberta dos intérpretes da constituição: contribuição para a interpretação pluralista e "procedimental" da Constituição. Tradução de Gilmar Ferreira Mendes. Porto Alegre: Sergio Antonio Fabris, 1997. Reimp. 2002. [Título do original: Die offene Gesellschaft der Verfassungsinterpreten. Ein Beitrag zur pluralistischen und "prozessualen"Verfassungsinterpretation.]

JUSTEN FILHO, Marçal. Curso de direito administrativo. 2. ed. São Paulo: Saraiva, 2006. O direito das agências reguladoras independentes. São Paulo: Dialética, 2002. 
KRELL, Andreas J. A recepção das teorias alemãs sobre “conceitos jurídicos indeterminados” e o controle da discricionariedade no Brasil. Revista Interesse Público, Porto Alegre, v. 23, p. 21-49, 2004.

LaUbadère, André de. Direito Público Económico. Tradução de Maria Teresa Costa. Coimbra: Ed. Almedina, 1985. MADARIAGA GUTIÉRREZ, Mónica. Seguridad juridica y administración publica en el siglo XXI. 2. ed. Santiago: Jurídica de Chile, 1993.

MARQUES NETO, Floriano Peixoto de Azevedo. A nova regulação estatal e as agências independentes. In SUNDFELD, Carlos Ari. (Org.) Direito administrativo econômico. São Paulo: Malheiros, 2000.

Pensando o controle da atividade regulação estatal. In: GUERRA, Sérgio. (Coord.) Temas de direito regulatório. Rio de Janeiro: Freitas Bastos, 2004.

MEDAUAR, Odete. $O$ direito administrativo em evolução. 2. ed. São Paulo: Revista dos Tribunais, 2003.

MEILÁN GIL, José Luis. Progreso tecnológico y servicios públicos. Madrid: Civitas, 2006.

MORAES, Alexandre de. Agências reguladoras. São Paulo: Atlas, 2002.

MORAES, Germana de Oliveira. Controle jurisdicional da administração pública. São Paulo: Dialética, 2002.

MOREIRA NETO, Diogo de Figueiredo. Governo e governança em tempos de mundialização: reflexões à luz dos novos paradigmas do direito. Revista de Direito Administrativo, São Paulo, v. 243, p. 41-47, set./dez. 2006.

Mutações do direito público. Rio de Janeiro: Renovar, 2006.

Direito regulatório: a alternativa participativa e flexível para a administração pública de relações setoriais complexas no estado democrático. Rio de Janeiro: Renovar, 2003.

MOTTA, Fabrício Macedo. A função normativa da administração pública brasileira. 2007. 217 p. Tese (Doutorado em Direito do Estado). Universidade de São Paulo.

MÜLLER, Friedrich. Discours de la méthode juridique. Tradução de Olivier Jouanjan. Paris: Presses Universitaires de France, 1996.

OTERO, Paulo. Legalidade e Administração Pública: o sentido da vinculação administrativa à juridicidade. Coimbra: Almedina, 2003.

PAREJO ALFONSO, Luciano. Administrar y juzgar: dos funciones constitucionales distintas y complementarias. Madrid: Tecnos, 1993.

PERLINGIERI, Pietro. Perfis do direito civil: introdução ao direito civil constitucional. Tradução de Maria Cristina De Cicco. Rio de Janeiro: Renovar, 2002.

RÁO, Vicente. $O$ direito e a vida dos direitos. 5. ed., anotada e atual. por Ovídio Rocha Barros Sandoval. São Paulo: Revista dos Tribunais, 1999.

SOUTO, Marcos Juruena Villela. Direito administrativo regulatório. Rio de Janeiro: Lumen Juris, 2002.

TOJAL, Sebastião Botto de Barros. Controle judicial da atividade normativa das agências reguladoras. In:

MORAES, Alexandre de. (Org.) Agências reguladoras. São Paulo: Atlas, 2002.

TORRES, Ricardo Lobo. Tratado de direito constitucional financeiro e tributário. Rio de Janeiro: Renovar, 2005. v. 2. ZAGREBELSKY, Gustavo. El derecho dúctil, ley, derechos, justicia. Tradução de Marina Gascón. Madrid: Trotta, 1995. [Título original: Il diritto milte: legge diritti giustizia.]

Sérgio Guerra

Praia de Botafogo, $190-13^{\circ}$ andar Botafogo - 22250-190

Rio de Janeiro - RJ - Brasi sergio.guerralafgv.br
Pós-Doutor em Administração Pública, FGV/EBAPE

Doutor E MESTRE EM Direito

Professor Titular de Direito Administrativo dos cursos de Graduação e de Mestrado em Poder Judiciário

DA DIREITO GV/ RJ 